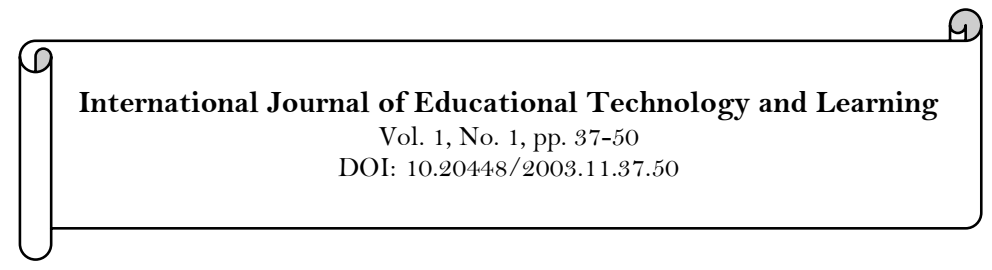

\title{
Student-Centered Learning: Moving Towards Mass-Customization in Higher Education
}

\author{
Herbert Rau ${ }^{1}$ \\ ${ }^{1}$ Associate Professor of Marketing Utica College Utica, New York
}

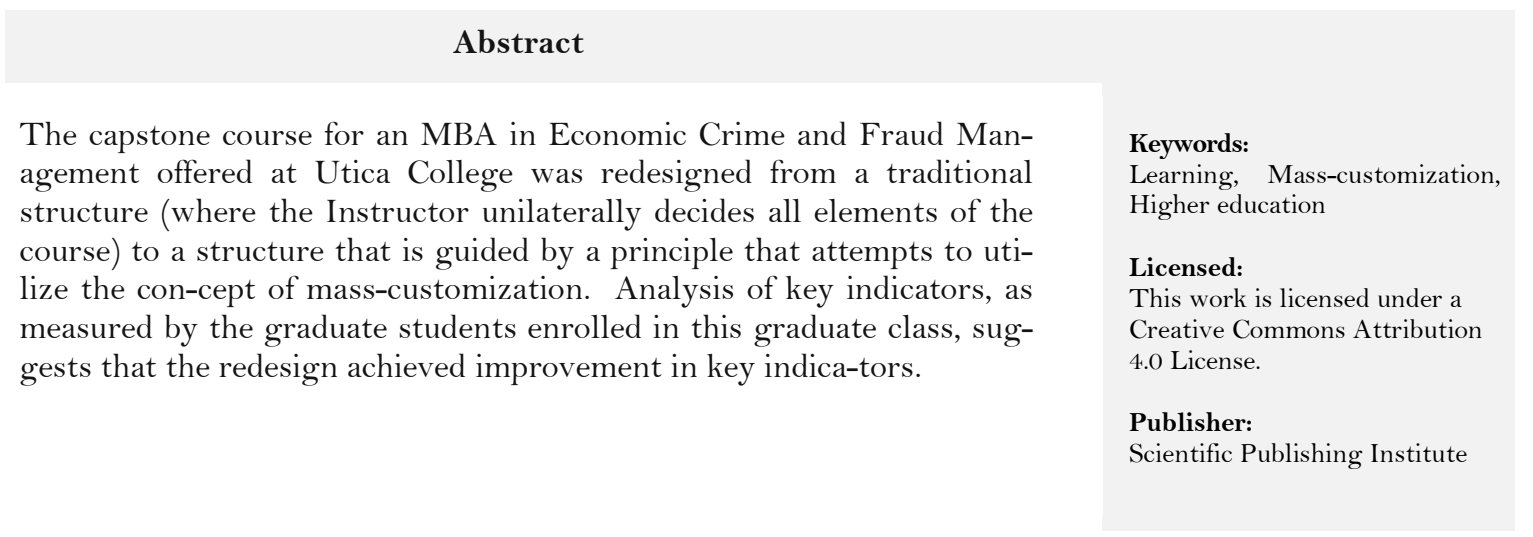

\section{Introduction}

Hawk and Shah (2007) have noted that students have different preferred styles of learning. These styles of learning are both hereditary and 'learned' by individuals as they engage as active members of society. While it appears that the most frequent method for contemporary education in post secondary schooling is the lecture, other methods of teaching appear to be not as common. As Hawk and Shah discuss in their paper, their are other modes of learning. Kolb Gregorc, Felder-Silverman, Dunn and Dunn, and VARK are cited as examples of models that recognize that students have different preferred means of learning. Many other scholars have noted the diversity of learning styles and preferences for humans including (Allitt, 2010; Antonancopoulou, 2006; Antonancopoulous \& Chiva, 2007; Binsted, 1980; Brockbank, McGill, \& Beech, 2002; Drummond, 2016; Elkhannoubi, 2016; Honey \& Mumford, 1992; Irfan, 2016; Islam, 2013; Kaufman et al., 2010; Kolb, 2014; Kolbs, Rubin, \& McIntyre, 1984; Macpherson, Jones, Zhang, \& Wilson, 2003; Pashler, McDaniel, Rohrer, \& Bjork, 2008; Pasupathi, 2012; Perry, Samuelson, Malloy, \& Schiffer, 2010; Rau, 2012; Raus, 2009; Schaler, 2006; Truong, 2015). From the writing of these scholars, this paper takes the position that individuals have preferred styles of learning.

However, many post-secondary course seem to be designed to deliver course content in a predominant manner, whether it is a lecture format, or student discussion and debate. The problem of course-content delivery is compounded via the constraints that are inherent for an on-line learning course. To address that concern, a design structure that attempts to achieve a mass-customization of course content delivery was created. Mass-customization is a concept that is familiar to the commercial sector. That concept envisions a blending of the ideals of mass production, integrated into a customer preference for 'one-off' products and services. To be successful, the efficiency and effectiveness that are hall-mark of mass production, must be costeffectively combined with the elegance and individuality of custom delivered products and services.

\section{Modified Mass-Customization Design}

In an attempt to create a 'mass-customized' offering for a course that addresses strategy and leadership, the students are provided with eight distinct pre-selected paths: General Strategy, Global Strategy, Sustainability, Entrepreneurship, Leadership, Crisis Management, Managing in the Public Sector, or Fraud Investigation. Further, individual students may offer a proposal for a path that differs from the eight noted above. For students who prefer to follow a traditional format where all elements and actions are determined by the instructor before the course begins, a different path has been created that focuses on the broad topic of strategy and leadership. 
It is important to note that the capstone course is presented to graduate students who are predominately working adults. In that regard, it must be remembered that these students are adult learners with specific expectations and specific experiences. Following from the work of Brocket (2016) there are one dozen aspects of adult learners that must be considered:

1. Most adults are actively involved in learning and undertake at least one learning project every year.

2. Adults have the ability to learn successfully throughout their lives.

3. Adult learners bring a wealth of experience to the teaching-learning setting, and this experience can be a valuable resource.

4. It is important to recognize that decision the instructor makes about how the instructor will teach are based on whether the instructor is trying to change attitudes and values, skills and performance or knowledge and factual information.

5. Most adult learning is self-directed.

6. The need for adult learning is often triggered by some kind of developmental transition or crisis.

7. Adults choose to learn for many different reasons and the instructor needs to know what these are.

8. It is important to understand something about motivation and how the instructor can use motivation strategies to help excite the learners about what the instructor is teaching and, in some cases, to help break down learner resistance.

9. Teachers of adults need to understand the many kinds of barriers that can limit whether adults choose a learning activity or stay with the activity.

10.Understanding learning styles is important, but it is often misunderstood and misused.

11. Most successful adult learning takes place in a collaborative or cooperative string, where sharing and synergy are crucial.

12.The ultimate purpose of adult education is to help learners think for themselves.

The aspects noted by Brocket are utilized as foundational concepts with the modified design structure. Following are select portions of the syllabus for the capstone class that explains the design strategy and requirements.

\section{Syllabus Excerpts \\ 3.1. Teaching Strategies}

- This course will combine a wide variety of modes for learning including:

- Virtual Residency (via Adobe Connect or the Big Blue Button)

- Discussions (student and instructor lead - on line)

- Readings and Problem Assignments

- Individual Chosen Materials

○ Individual Reflections

Fundamentally, this course is learner-centered designed. You, the student, will have a significant choice in what you will learn, how you will learn it, and how you will demonstrate that you have acquired competence regarding the topic of strategy. While you will be required to take approximately $1 / 2$ of the course materials as determined by the instructor, you will have the opportunity to choose from a variety of pre-selected materials what you want to study and learn for the other $50 \%$ of the course materials.

This course design is unique in that it will simultaneously allow for both a broad and diverse appreciation of different focal areas of strategy, as well as the ability to explore in depth any topic for which the student is most interested. In order to take optimal advantage of this design, students should adopt a 'Learning Community' perspective. That is, because each student will focus on an arena of personal interest, they will develop a more in-depth understanding of that focal area than potentially other students in the class. Therefore, each student will in essence become an 'expert' for their topic, and will be able to share their learnings of that specialty with their classmates. Consequently, as each student is submitting work that will be viewed by the entire community (for example, discussion posts), please consider yourself as the individual who has discovered new information that may be of value and help to your colleagues.

However, if too much choice makes you panic, you may also choose the option where the instructor selects all of the material that you will utilize to complete the course. The class schedule of this material is noted at the end of this syllabus.

\subsection{Course Requirements}

Percent breakdown for MGT619 for the required components of the course:

- Case Analysis

$30 \%$

- Module Paper

$40 \%$

- On-line discussion

$30 \%$

Percent breakdown for the student chosen components of the course determined by the student contract that has been 'signed-off by the instructor. The below does not apply for students who have 
chosen the traditional path where the instructor chooses all of the required materials. In that case, the breakdown for grading is noted above.

Percent breakdown for the totality of selected components of the course:

- Instructor Selected $50 \%$

- Student Selected with Instructor Acceptance $50 \%$

\subsection{Module Paper}

I thought it might be helpful if I provided a few more words regarding the $15+$ page paper which is due at the end of the course (end week 7, beginning week 8). This is a paper that gives you a lot of freedom. From the readings of this semester and your entire program, please write about the aspect of strategy that most interests you (identified by you during the first week of the class), relates to your career and career objectives, and most likely relates to Economic Crime. I am most interested in your critical thinking and analytic abilities. In that regard, you might want to review the PowerPoint presentation I presented during our first Virtual Residency (and are available in your materials).

Your paper should not be a 'rehash' of a previously submitted paper for either this course or another course within the program. However, if you are interested in extending your exploration of a previously submitted topic with greater depth and knowledge, that would be fine. You should also keep in mind that this is an academic paper and it should represent your accumulated knowledge of your discipline from your studies in this program.

Write about something that interests you, and will also 'show-case' what you have learned. Also, where appropriate, include any information you have learned from your other course work during the program. You might consider writing about your organization, an organization with which you are familiar or might have worked for in the past, or possibly a recommendation for society to improve an issue you have identified. Giving you some examples of what I have received in the past were papers on piracy, economic crime in Iran, Pakistan, Mexico, Nigeria, the jewelry industry in South America, as well as a recommendation for improvement in the Federal government for fraud prevention.

\subsection{Course Components Time Estimates (Required and Potential)}

Required

-Text Readings

-Case Studies

-Discussion Posts

25 hours (Syllabus)

23 hours (Syllabus)

24 hours (Syllabus)

72 hours

Optional (Choose Any Combination Equaling Approximately 70 hours)

-Simulations 17 hours (Advanced Strategic Management - Marketplace)

-Board Games 6 hours (Beer Game (Computer Version); Pandemic; Oregon Trail;

Justice League: Axis of Villains; The Game (card game))

-Synchronous Chat $\quad 10$ hours (?) (TBD)

-Book Groups 25 hours (Suggested Reading Lists in Engage)

-Mini-project (group?) 50 hours (?) (TBD with others)

-Reflection Papers 12 hours (From Readings, Discussion Posts, etc.)

-Lecture (student lead) 8 hours (Virtual Residencies, Embedded Engage Files)

- Individual Project 25 hours (TBD)

Be sure when creating your schedule that you are not 'back-end' loaded. That is, submit work on a weekly basis during the semester, and not all during the last week of class.

\section{Additional Comments Regarding the Syllabus}

Utilizing either the Traditional Path, or a Student-centered Path, course content is measured using a 135 hour minimum contact time for required or self-selected work. A significant number of students easily exceeded the contact-hour requirement. Estimated time for individual activities were determined by the instructor using the instructor's reading and writing speed, and personal engagement time with the other activities.

To supplement required text readings, separate reading lists were created for books, journals, and web sites for each path. As much as possible, these additional reading lists were designed to present students with free or inexpensive materials, and to serve as a useful resource for future use as the students progressed through their careers.

\section{Methodology}

The assessment survey questions are subjective in nature and were completed voluntarily by the students. It might be argued that subjective evaluations completed by students lack necessary 'rigor' from a quantitative perspective as an assessment instrument. These questions are more concerned with the 'process' and structure of the course, and as to whether the course objectives were achieved. It might be argued that in 
this specific case - a capstone course within a graduate professional program - where the evaluation is being performed by working professionals (many with middle and senior managerial responsibilities), is actually highly valuable because these working professionals intimately know and understand the requirements of their industrial sector and are frequently the same individuals who are evaluating the performance of their associates, and are also responsible for the profitability and survivability of their organizations. As such, they may be considered valid assessors.

The survey was administered during the last week of the class. The survey was prominently posted on the Engage (Moodle) learning platform at the beginning of the semester to alert the students of the survey's presence in the course. Students were informed that the results of the survey were being used to improve the design structure of the class. Participation was voluntary, and survey responses were submitted into a 'drop box' that was embedded within the course shell. Twenty-four students submitted responses for classes that were conducted before the design change, and seventy students submitted responses for classes conducted after the design change. The returns ratio for the before-design change was approximately $67 \%$, while the return ratio for classes after the design change was approximately $95 \%$. Approximately $63 \%$ of students chose to follow a traditional path. Results from the survey were entered into JMP for analysis.

\section{Student Comments Regarding Choice of Traditional Path}

Following are comments noted by students that decided to choose the Traditional Path for course design (where the instructor chooses all of the materials for the course and the sequence of activities):

"I looked through all of the readings from the traditional path and found them to appear interesting. The book choices also looked as though they would apply to my current occupation and would help achieve success in future endeavors. I did not believe the other paths would have been more beneficial to future goals than the tradition(al) path, which is why I stuck with that one."

"Honestly, though I am a person who believes life is full of learning and can take any format, recently there has been too much going on from every perspective. I like thinking. In fact, people often tell me that I think too much. I appreciated the option to have shaped my own learning however, when looking into which non-traditional path I wanted to take, I found myself thinking too much and right now there's too much thinking going on in life right now. I think about where my spouse and I are headed, financial situation, to have/not have children, work situation, increasing visibility at work, parent's old age and health conditions, etc... The list is endless right now and so I chose the traditional path so I didn't have to think too much about where I'm headed and how I'm going to get there. I just wanted someone to tell me what to do and how to do it."

"I think the biggest reason for me to choose the traditional path was because it primarily eliminated all unknowns. The course was predictable. Besides that, I hold a second job on weekends and I believe I didn't have a lot of experience in the topics that could have (been) more relevant for the class. It definitely made it easier for me to choose the traditional path."

"My initial thought during the virtual residency was that the course option to be creative required a lot more planning and the traditional path had minimal. After going straight through the program, I was "burnt out". In my case, if the professor made no option for the traditional path I would have had no problem doing the other path and would have been successful, so for me it would have been better to not have the option. I say this because throughout the program there have been several assignments that I did not enjoy at all but because they were required I did what I had to do. I think the concept of the course is great and I enjoyed reading my other classmates posts about the areas they read. Honestly as I made the decision to do the traditional path and even now, I knew the non-traditional was a better option and I would have benefited from that path."

"It was a combination of being tired and my anticipated workload over the 8 weeks. At my job, my boss resigned and I was trying to "shine" and prove myself, by accepting some of his workload. I didn't have the time or energy to develop my own path. I really like the idea of being able to develop my own course. I think overall, the students enjoy and appreciate the flexibility."

"The reason I picked the traditional path was actually due to my learning style. I prefer structure and knowing exactly what is expected and when. The traditional path leaves little to wonder about, especially when trying to balance work and school. I certainly see the value of the non-traditional path and found it interesting to be able to kind of build and choose my own syllabus from a wide variety of choices. Given a traditional 16 week semester, I definitely would have loved to try the non-traditional route!"

"The survey questions don't do this class justice. The blended aspect of the class greatly enhanced the learning experience. This is a Master's level program and the structure provided by the professor afforded the student to show "mastery" of the topics....Giving the students their own choice for topic was awesome, I wish it was applied throughout the program."

"I thought we all worked really well together and overall I was glad that I went this route with a group project. I really enjoyed the options for this class, the ability for some of the class to go the traditional route and the ability for those who wanted to go outside of the box to do so." 
"There wasn't really enough time at the beginning of the course to figure out everything we'd need to for the blended path. Seemed like a lot to plan out in a very short amount of time. Plus I'm not very creative, so it was better for me to just follow a path that was already laid out."

"I was truly confused by the syllabus and the contract. After working through the course, it became clearer. I think the use of hyperlinks in the syllabus and writing up the contract in a word document rather than the excel spreadsheet might make them more readable."

"I chose the Traditional Path for two reasons, I had purchased my books way in advance of the class and I was away on vacation for the first week. Knowing myself, I'm 99\% sure I would have chosen the Traditional Path regardless, because I liked that everything was already spell out and I knew what to expect. But looking back on it now, I think I could have had more fun with the assignments if I had chosen my own path. Either way, it was a great class and I learned a lot!"

"The timing of this course being around the holidays, as well as, a house move made this course difficult. The traditional path made more sense for me in regards to time available for the course each week. I would've loved to choose my own path and learn more about where my interest lies and it's a great concept for a graduate class."

"I enjoy structure when I am learning."

"I chose the traditional path because I am used to having a clear structure on my courses, and I enjoyed the traditional format that was predictable and easy to accomplish."

"I decided to follow the traditional path mainly due to the fact that I do not have the time to create my own self-study program. I work a 45-50 hour work week, and in school full time so I just do not have the time."

"Although I was tempted to take the blended path, I chose the traditional path simply because everything was all planned out, easy to follow from week to week, and the books sounded very interesting to read. I think it was great having the choice to decide which path you wanted as no other professors in this program ever gave us that option. I also feel it created a better discussion among all the students each week. You weren't reading the same post from everyone so it was nice to have an open discussion about a topic you weren't learning about yourself that week."

As may be noted in the above observations from students choosing the Traditional Path, three categories are cited:

1 Some students prefer clear structure and order

2 Some students did not have the available time or inclination to create their own path for learning

3 Some students were more interested in the material that was required for the Traditional Path.

\section{Student Observations Regarding Discussion Posts: (Overall Comments - Pre-Design Change)}

In addition to the opinions being expressed by the students regarding their choice of educational path, some students also commented on the required discussion post element of the course. Their comments are noted below:

“The discussion posts for the entire degree left me lacking. I don't want to rehash the chapter I just read, and I don't want the summary of other students. I'd rather see the professor create questions that make the students apply the knowledge. "How does the current lawsuit for company" $\mathrm{X}$ " in the media apply to the topics we just read this week?" of "Given 'topic Y' what companies do you feel employ this methodology effectively?" My thought on this is that the discussion 'requirement' feels like a 'check the block', if you want a discussion you need to force the issue in an online environment. I want my ideas or supposition to be questioned and analyzed."

"I feel that a lot of your courses are close to entirely reading/writing based, which adding other facets might help diversify the student's learning. I don't know if it is just my opinion, but I feel discussions are just another short paper we write with little added value with the "discussing" aspect."

"I think the discussion (posts) is a great way to see other classmate's perspectives and expand your thinking on the subject matter. The reason I did not score this higher was that some classmates seemed as though they did not take the discussion (posts) seriously. While we were in week 7 of the course, some students were still posting their initial posts to the week 4 and 5 . (some students were always 2-3 weeks behind the entire course). By that time, the focus was off of that week's material and onto the most current week. Therefore their late posts did not really contribute to the learning and purpose of the discussion boards."

8. Student Posts Regarding Discussion Posts from Other Students for the Mass-Customized Design: (what the students actually wrote in their reply discussion posts and as these posts relate to the mass-customized design and that each student would become a 'topic expert' because of their chosen path):

"I want to start out by telling you how much your posts have taught me this semester. I don't always comment, but I always read them and I always have a take away from your posts that I go back and check on to make sure we are protected from some of the things that you talk about. My IT department has been won- 
dering what it is I have been doing this semester because I have been coming to them often to ask them questions that have stemmed from your posts. I think that may end up being a double-edge sword...when they talk to me half the time I have no idea what they are saying. It is like they have their own language. I have often been told the same things when I give a financial presentation. You start to recognize the signs, the glazed look, the smile and nod... Your posts have detailed some of the things that they talk about, which I have been grateful for. The downside is now they think I speak their language! Seriously, it has been a win/win on both sides. So thank you for that."

"You have convinced me to read a new book. I would like to learn about more techniques that are out there to combat fraud. However, I think the key point you hit on is that we can never take people out of the equation of fighting fraud. There is intuition and complex human behavior that software and programs cannot account for. I look forward to reading the book."

"I had already made a note to read this case study, but now am looking forward to reading it sooner than later. I am currently as a cross-road in my career and had been looking for a while to achieve that "work-life balance" myself. I'm not particularly happy in my current position and definitely don't feel like I'm giving it my all. This is mainly due to the position I'm in and not effort on my part. I had read somewhere before, in this or a previous course, that if you find something you enjoy doing, it won't feel like work and that in itself should help to create a more balance life. This is what I'm hoping to achieve in the near future. Thanks for the Inspirational post!"

"Your topic was very closely related to my chapter this week. Above you said, "the primary task facing organizations, which is to manage their relationship with other organizations." This is very true with regards to supply chain management. And accounting fraud plays a large part in inventory control and management as well. It is interesting that push for organizations to be competitive and to be risk adverse starts with clear management of its relationships with other companies."

"Well I can certainly say that you have been extremely thorough in your summary of the chapters that you read this week. The more I read about the books in the traditional path, the more I wish I was reading them. However, I'm happy that I get to read so many different interpretations of the chapters regardless. I was particularly interested in the description of chapter 5 of the Destructive Leaders and Dysfunctional Organizations book. It reminds me very much of some similar problems that we are having at that bank that I work for."

"I enjoyed your post. I'm on the Mastering Strategic Management path, so it is interesting to read your post because of its technical nature and difference in structure of my chosen path. Your summation of the chapters gave great information. With Information Security and technology I think your point that attackers are one step ahead and one small opening can do a lot of damage."

"Excellent post. I find it very interesting the book that you choose to outline, and your summary of the chapters is very detailed which helps someone who hasn't actually read the chapter to understand it."

"Excellent post. I want to read the book you outlined now. I thought it interesting the comment on poor leadership and the link to mental illness. I agree with Patrick's response and in my experience poor leadership is almost always linked to ineffective change management. I think a lot of poor leadership is tied to the inability to manage change, or the change themselves. This was a point that was made in the book I chose to read this week, Mastering Strategic Management."

"I enjoyed reading your posting. My learning path this semester does not include reading the "Organizations and Organizing" text; therefore, I appreciated the opportunity to learn about some of the concepts from that text. I have an example from work which relates to people behaving based on what is expected from them."

"You did a really nice job of honing in on some of the important take-aways from the chapters of the two books you read and from the case study. I am reading a different book, and despite this was able to get a really good idea of what the books you're reading are about. I particularly like your analysis of the Destructive Leaders and Dysfunctional Organizations book, and it actually made me wish that I had chosen to read that book because it sound very interesting."

"All of your readings this week sound very interesting. I think you touched upon several key points. I was especially interested in your discussion regarding human error and how security breaches have serious consequences for companies and how often these are the result of simple human error...."

"Kaitlyn, I've enjoyed reading your posts throughout the last several weeks. I wish I had picked the route you did but guess it's too late for that now :) I feel like the majority of the fraud related discussion throughout the courses here at Utica have mostly involved internal fraud. But in my opinion, the public is more knowledgeable and more concerned with external fraud. I just as mentioned by Danielle, it's the most common type of fraud experienced by the general public."

As noted in the postings from the students to their colleagues in the redesigned course, it appears that allowing students to choose multiple paths and interests for this particular course (MGT619) has broadened the student's perspective and understanding. It is inferred from these posts that the variety of learning paths presented in the course design has deepened the student's learning and curiosity to learn more in keeping with Bloom's taxonomy (1956). 


\section{Results}

The assessment survey utilized was composed of 28 questions; two questions were demographic in nature, ten questions asked the student their preferred learning style and orientation to processing their environment, one question asked students who followed a Traditional Path why they made their choice for the Traditional Path, four questions focused on student interaction, and the remaining eleven question inquired as to whether the course achieved the designed purposes. With the exceptions of the demographic questions, two questions relating to preferred learning style and orientation to their environment, and the one question focusing on why Traditional Path students chose that path, all of the other questions were on a 9 point Likert scale.

The four question that explored the student interactions included:

1. How effective were your classmates in enhancing your learning?

2. How effective were you in advancing the learning of your classmates?

3. How effective was your utilization of your classmate's skills and knowledge?

4. How effectively did your classmates use your skills and knowledge?

The eleven questions that explored whether the designed purposes were achieved included:

1. Has this course expanded your style and methodologies of learning?

2. Has this course provided knowledge about yourself that you might not have learned in a different forum?

3. Do you believe that this course provided information that may be of use to you in your future endeavors?

4. Where the stated objectives of the course achieved (declared in the syllabus)?

5. Where the objectives of the course, that were not declared in the syllabus, but discussed in class, achieved?

6. Were you able to bring knowledge that you learned from other courses into this course?

7. How much new knowledge did you learn from this course?

8. If you learned new knowledge from this course, how important do you think it might be to achieving your goals and objectives?

9. Do you think that you enhanced your ability to think critically and analytically by taking this course?

10. Do you feel that you at least partially 'owned' the problems embedded with the design of this course (questions regarding strategy and leadership)?

11. After taking this course do you believe that you are better able to create a strategic plan that focuses on your selected area of expertise?

The following charts focus on the eleven questions that explored the relationship between student's responses to the design structure before the change to a modified mass-customized course, and after the change was initiated. The code of ' 1 ' corresponds to before the design change, while the code of ' 2 ' relates to after the design change. The ' $x$ ' axis represents the total responses for the student utilizing the 9 -point Likert scale.

1. Has this course expanded your style and methodologies of learning?

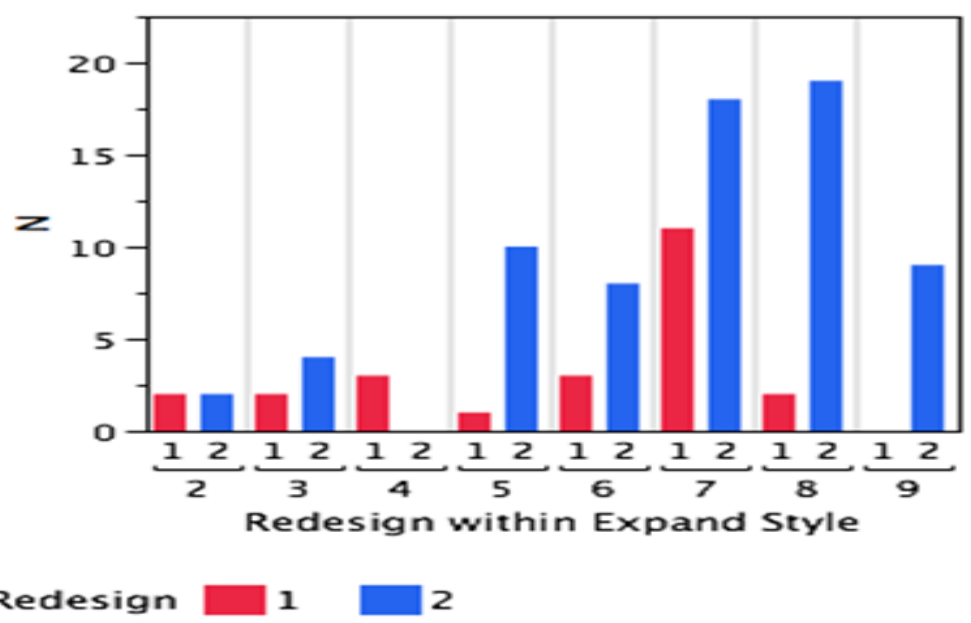

The relevant statistics for the chart noted above in question \#1 are (note that 'Conf.' is the abbreviation for the word Confidence for all of the following discussion):

$\begin{array}{llllll} & \text { Mean } & \text { Std. Dev. } & \text { Std. Error } & \text { Upper Conf. } & \text { Lower Conf. } \\ \text { Control } & 5.75 & 1.87 & .38 & 6.54 & 4.96 \\ \text { Mass-Customized } & 6.76 & 1.76 & .21 & 7.18 & 6.33\end{array}$

2. Has this course provided knowledge about yourself that you might not have learned in a different forum? 


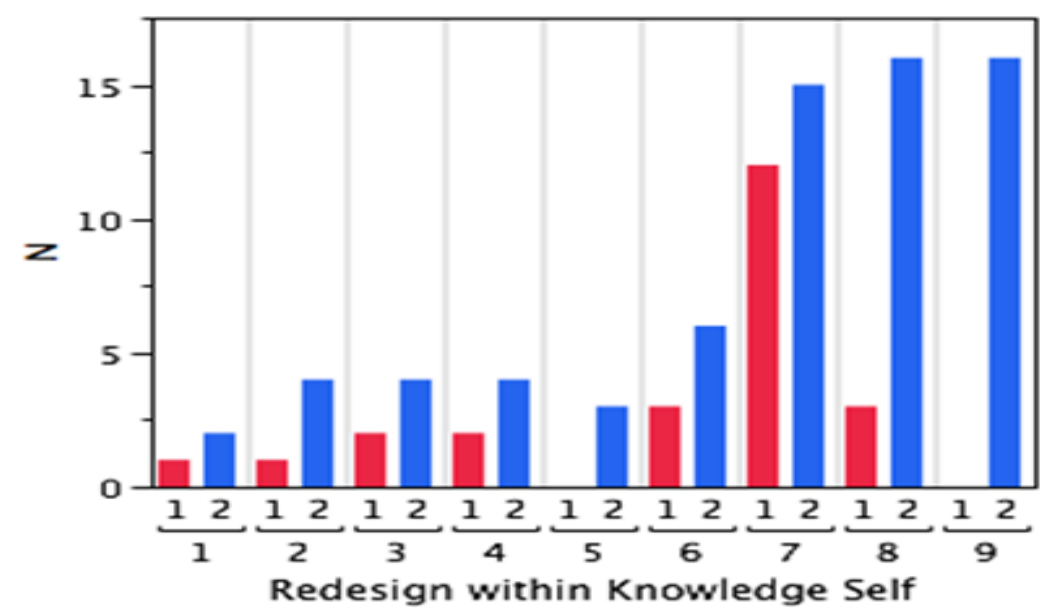

The relevant statistics for the chart noted above in question \#2 are:

$\begin{array}{llllll} & \text { Mean } & \text { Std. Dev. } & \text { Std. Error } & \text { Upper Conf. } & \text { Lower Conf. } \\ \text { Control } & 5.96 & 1.99 & .41 & 6.80 & 5.11 \\ \text { Mass-Customized } & 6.66 & 2.29 & .27 & 7.20 & 6.11\end{array}$

3. Do you believe that this course provided information that may be of use to you in your future endeavors?
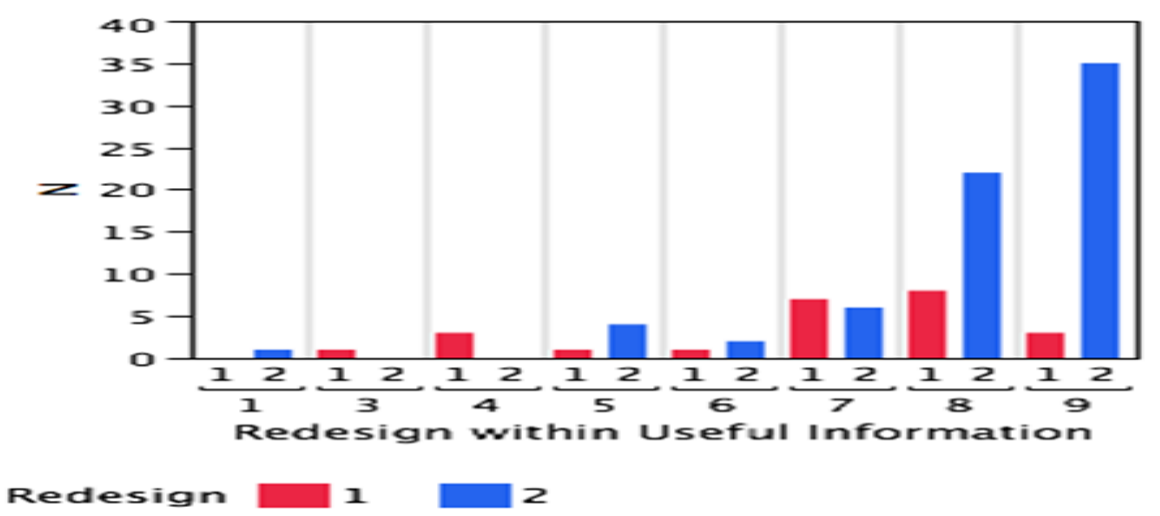

The relevant statistics for the chart noted above in question \#3 are:

$\begin{array}{llllll} & \text { Mean } & \text { Std. Dev. } & \text { Std. Error } & \text { Upper Conf. } & \text { Lower Conf. } \\ \text { Control } & 6.92 & 1.72 & .35 & 7.64 & 6.19 \\ \text { Mass-Customized } 8.09 & 1.39 & .17 & 8.42 & 7.75\end{array}$

4. Where the stated objectives of the course achieved (declared in the syllabus)?

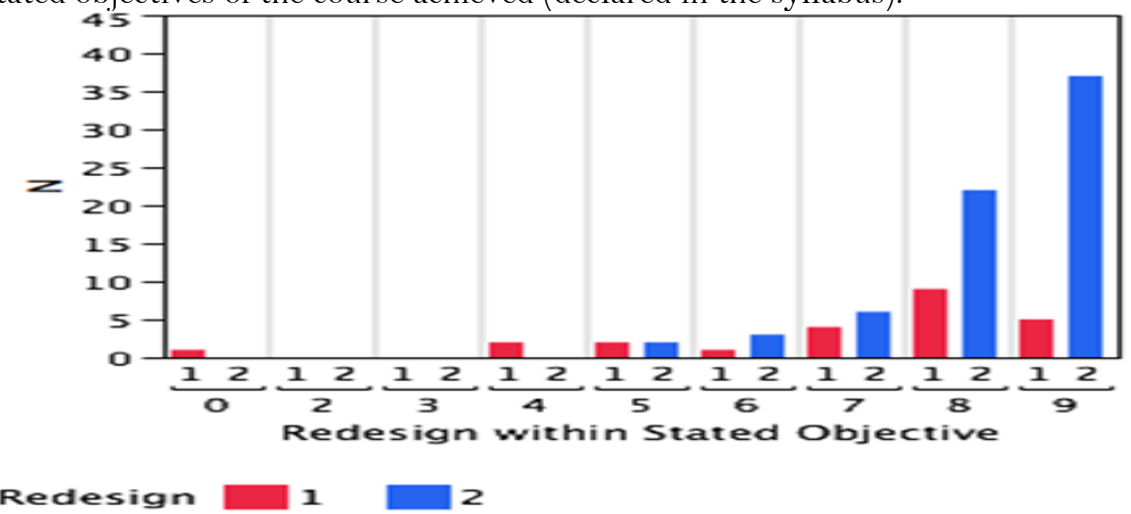

The relevant statistics for the chart noted above in question \#4 are:

$\begin{array}{lcllll} & \text { Mean } & \text { Std. Dev. } & \text { Std. Error } & \text { Upper Conf. } & \text { Lower Conf. } \\ \text { Control } & 7.04 & 2.14 & .44 & 7.94 & 6.14 \\ \text { Mass-Customized } & 8.27 & 0.99 & .12 & 8.51 & 8.03\end{array}$


5. Where the objectives of the course, that were not declared in the syllabus, but discussed in class, achieved? (Note, this question was not asked for the before design change classes).

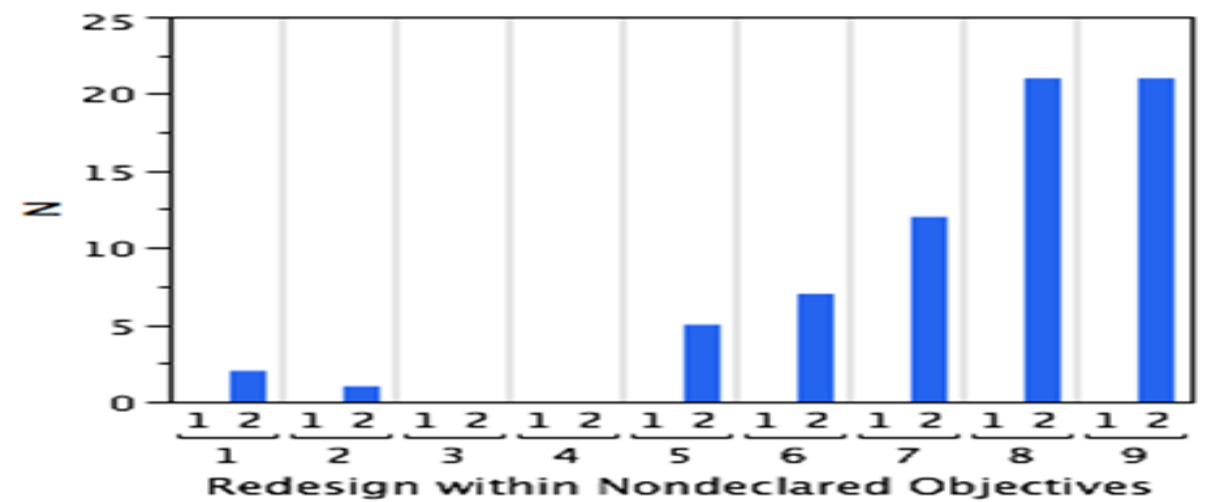

Redesign 12

The relevant statistics for the chart noted above in question \#5 are:

Control Mean Std. Dev. Std. Error

Upper Conf. Lower Conf.

Mass-Customized

$\begin{array}{ll}7.42 & 1.79\end{array}$

.21

7.85

6.99

6. Were you able to bring knowledge that you learned from other courses into this course?

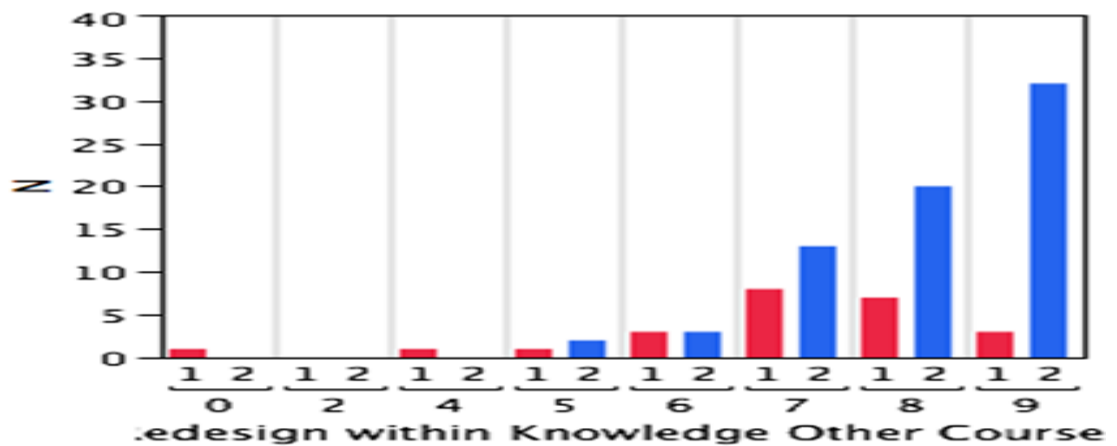

The relevant statistics for the chart noted above in question \#6 are:

$\begin{array}{lcllll} & \text { Mean } & \text { Std. Dev. } & \text { Std. Error } & \text { Upper Conf. } & \text { Lower Conf. } \\ \text { Control } & 6.92 & 1.91 & .39 & 7.72 & 6.11 \\ \text { Mass-Customized } & 8.1 & 1.04 & .12 & 8.35 & 7.85\end{array}$

7. How much new knowledge did you learn from this course?

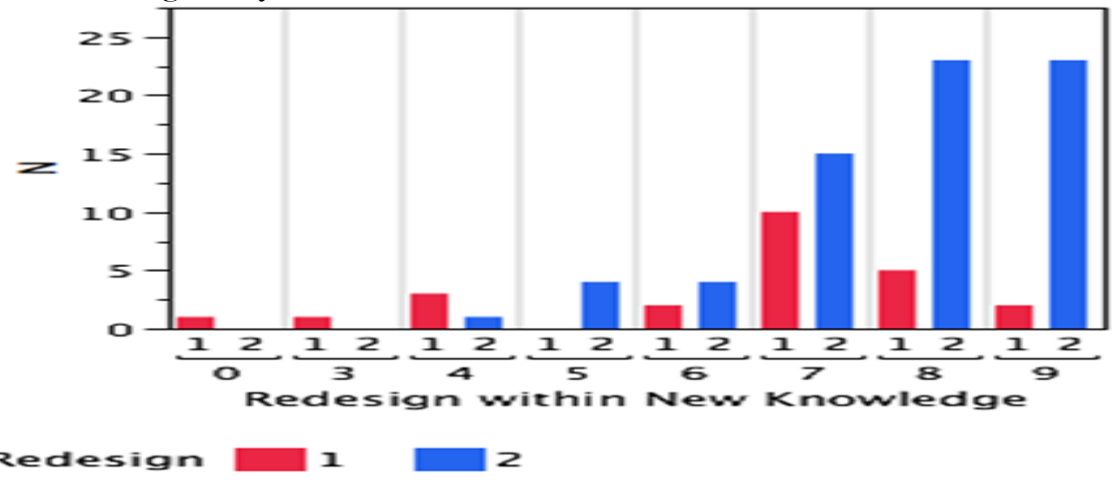

The relevant statistics for the chart noted above in question \#7 are:

$\begin{array}{lcllll} & \text { Mean } & \text { Std. Dev. } & \text { Std. Error } & \text { Upper Conf. } & \text { Lower Conf. } \\ \text { Control } & 6.46 & 2.08 & .43 & 7.34 & 5.58 \\ \text { Mass-Customized } & 7.77 & 1.22 & .15 & 8.06 & 7.48\end{array}$


8. If you learned new knowledge from this course, how important do you think it might be to achieving your goals and objectives?

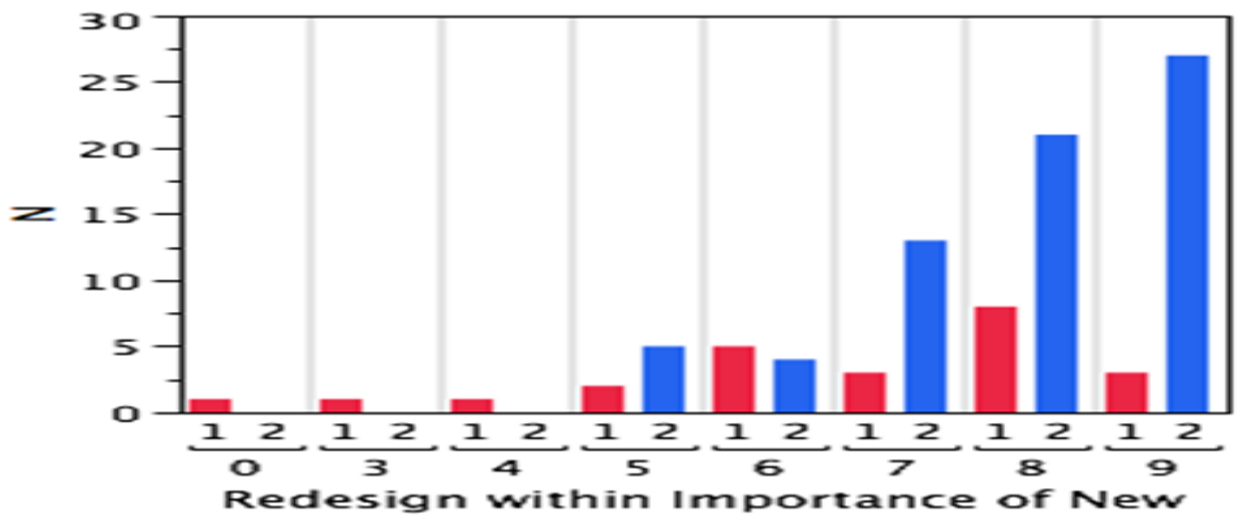

The relevant statistics for the chart noted above in question \#8 are:

$\begin{array}{llllll} & \text { Mean } & \text { Std. Dev. } & \text { Std. Error } & \text { Upper Conf. } & \text { Lower Conf. } \\ \text { Control } & 6.63 & 2.12 & .43 & 7.52 & 5.73 \\ \text { Mass-Customized } & 7.87 & 1.20 & .14 & 8.16 & 7.58\end{array}$

9. Do you think that you enhanced your ability to think critically and analytically by taking this course?

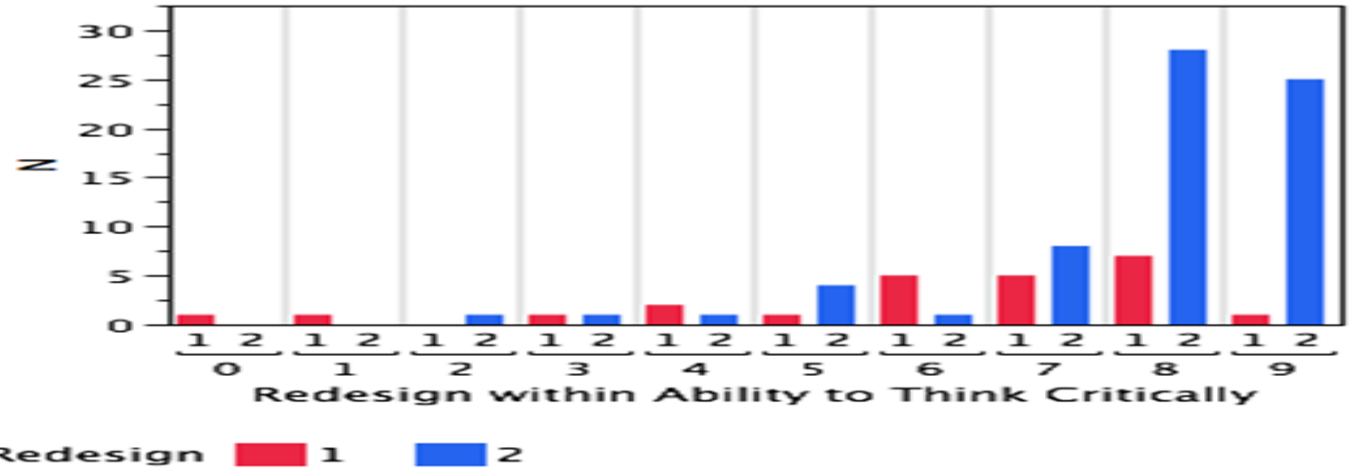

The relevant statistics for the chart noted above in question \#9 are:

$\begin{array}{lccccc} & \text { Mean } & \text { Std. Dev.Std. } & \text { Error } & \text { Upper Conf. } & \text { Lower Conf. } \\ \text { Control } & 6.13 & 2.29 & .47 & 7.09 & 5.16 \\ \text { Mass-Customized } & 7.83 & 1.47 & .18 & 8.18 & 7.47\end{array}$

10.Do you feel that you at least partially 'owned' the problems embedded with the design of this course (questions regarding strategy and leadership)?

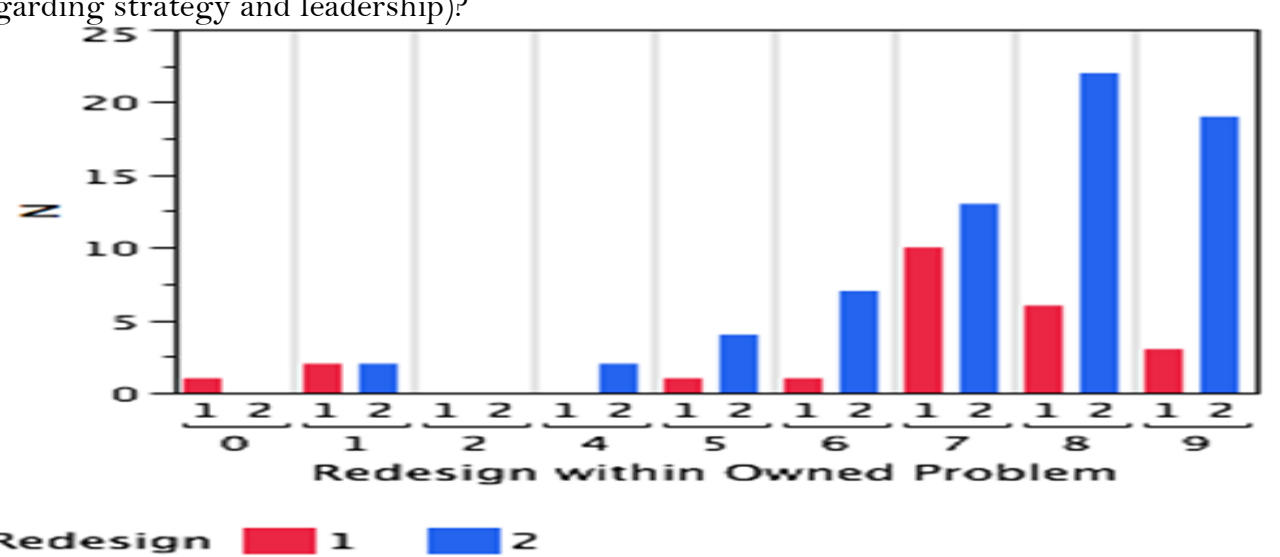

The relevant statistics for the chart noted above in question \#10 are: 


\begin{tabular}{|c|c|c|c|c|c|}
\hline & Mean & Std. Dev. & Std. Error & Upper Conf. & $\begin{array}{c}\text { Lower Conf. } \\
5.54\end{array}$ \\
\hline Customized & 7.39 & 1.72 & .21 & 7.80 & 6.98 \\
\hline
\end{tabular}

11.After taking this course do you believe that you are better able to create a strategic plan that focuses on your selected area of expertise?

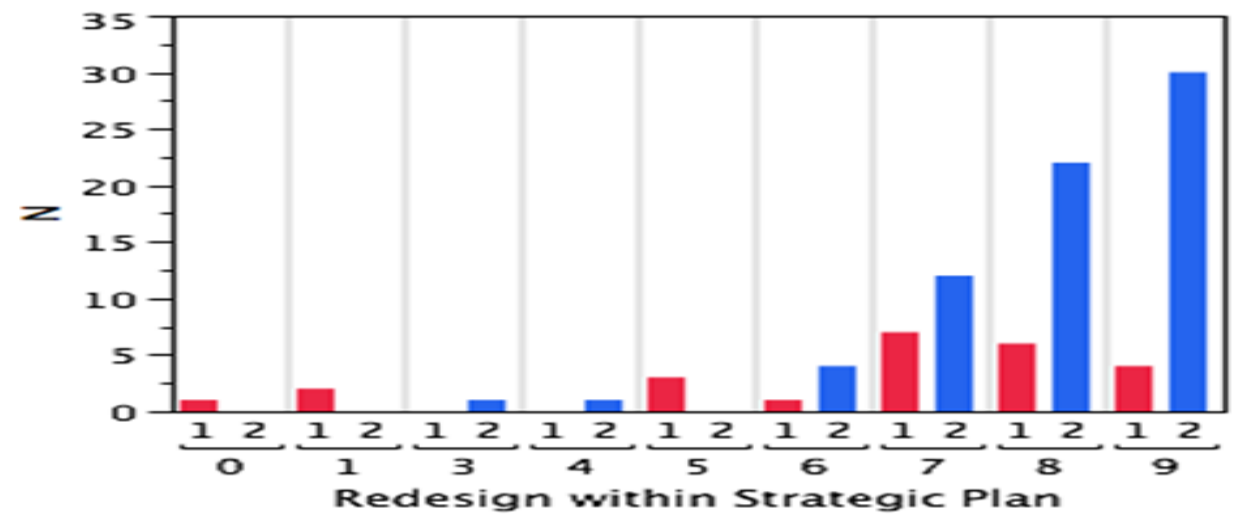

The relevant statistics for the chart noted above in question \#11 are:

$\begin{array}{lcllll} & \text { Mean } & \text { Std. Dev. } & \text { Std. Error } & \text { Upper Conf. } & \text { Lower Conf. } \\ \text { Control } & 6.50 & 2.55 & .52 & 7.58 & 5.42 \\ \text { Mass-Customized } & 8.00 & 1.20 & .14 & 8.30 & 7.73\end{array}$

The following four charts correspond to the question of course design and student interactions.

1. How effective were your classmates in enhancing your learning?

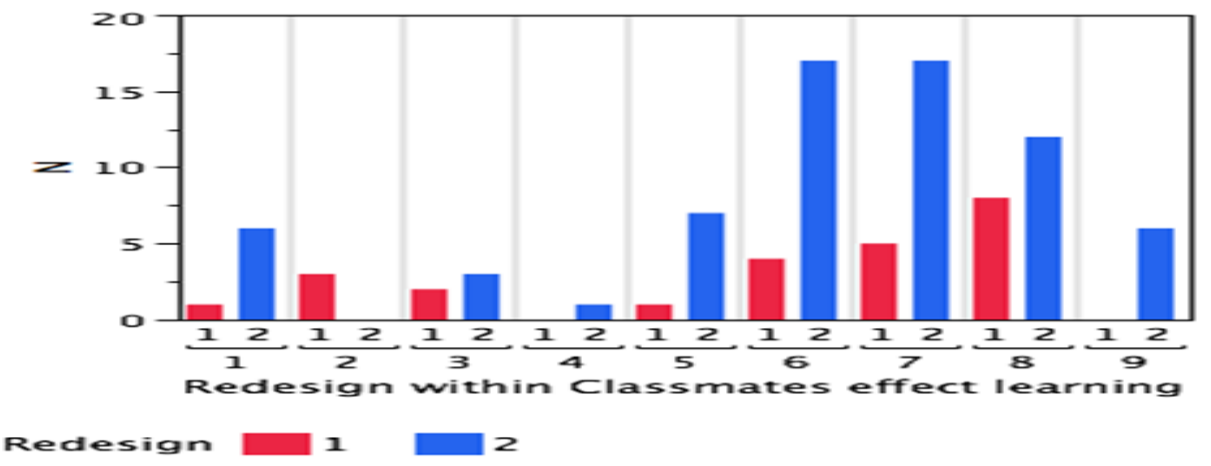

The relevant statistics for the chart noted above in question \#1 are:

$\begin{array}{lcclcc} & \text { Mean } & \text { Std. Dev. } & \text { Std. Error } & \text { Upper Conf. } & \text { Lower Conf. } \\ \text { Control } & 5.88 & 2.36 & .48 & 6.87 & 4.88 \\ \text { Mass-Customized } & 6.16 & 2.11 & .26 & 6.67 & 5.65\end{array}$

2. How effective were you in advancing the learning of your classmates? 


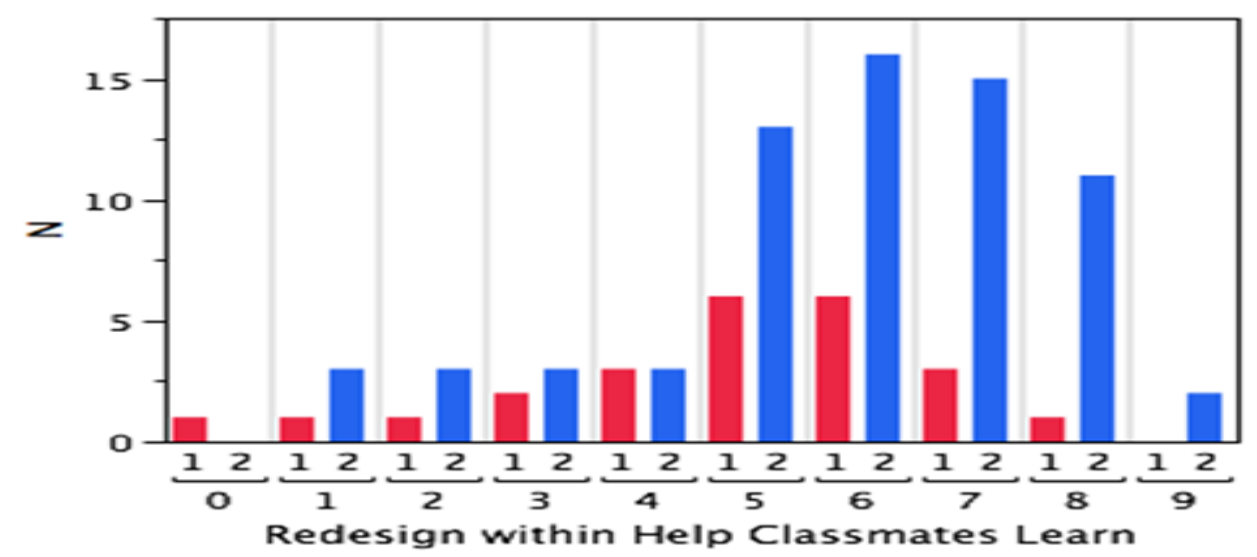

Redesign $11 \quad 2$

The relevant statistics for the chart noted above in question \#2 are:

$\begin{array}{llllll} & \text { Mean } & \text { Std. Dev. } & \text { Std. Error } & \text { Upper Conf. } & \text { Lower Conf. } \\ \text { Control } & 4.83 & 1.95 & .40 & 5.66 & 4.01 \\ \text { Mass-Customized } & 5.82 & 1.91 & .23 & 6.29 & 5.37\end{array}$

3. How effective was your utilization of your classmate's skills and knowledge?

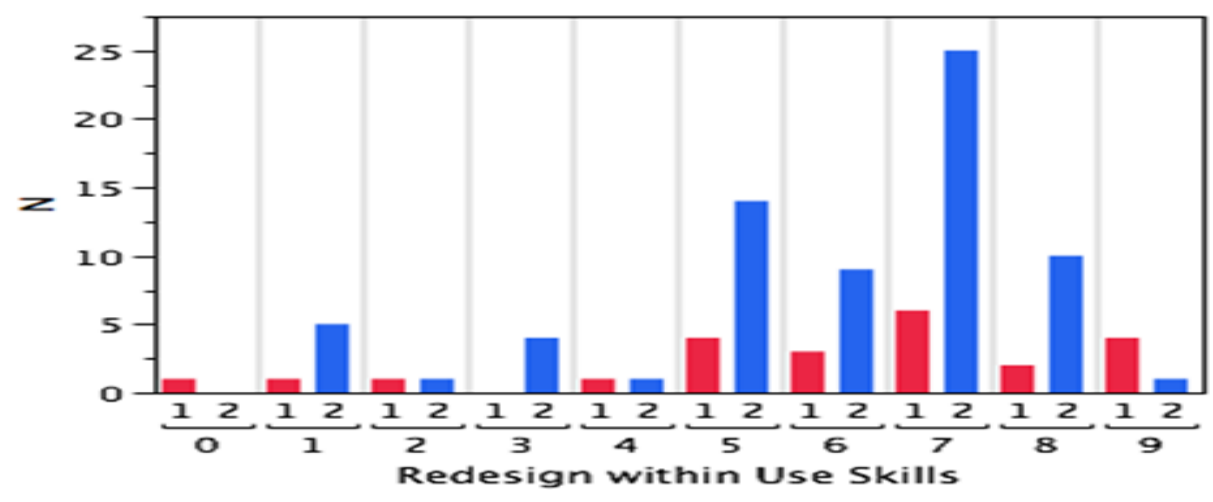

Redesign $1 \quad 12$

The relevant statistics for the chart noted above in question \#3 are:

$\begin{array}{lccccc} & \text { Mean } & \text { Std. Dev. } & \text { Std. Error } & \text { Upper Conf. } & \text { Lower Conf. } \\ \text { Control } & 6.04 & 2.48 & .52 & 7.11 & 4.97 \\ \text { Mass-Customized } & 5.87 & 1.97 & .23 & 6.34 & 5.40\end{array}$

4. How effectively did your classmates use your skills and knowledge? 


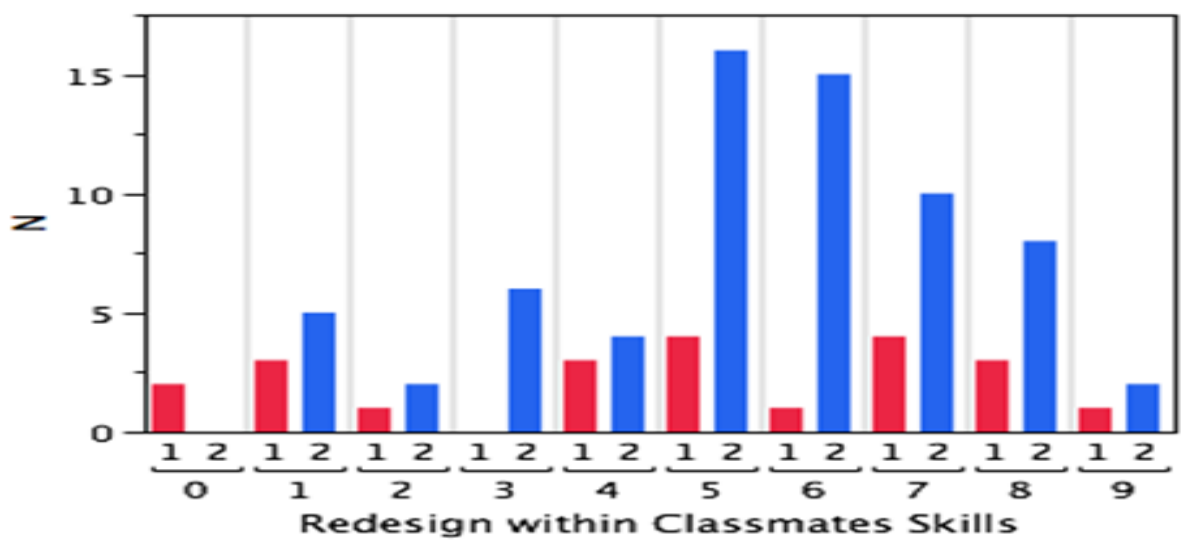

Redesign 1

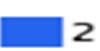

The relevant statistics for the chart noted above in question \#4 are:

$\begin{array}{llllll} & \text { Mean } & \text { Std. Dev. } & \text { Std. Error } & \text { Upper Conf. } & \text { Lower Conf. } \\ \text { Control } & 4.73 & 2.83 & .60 & 5.98 & 3.47 \\ \text { Mass-Customized } & 5.37 & 2.03 & .25 & 5.86 & 4.88\end{array}$

The various charts suggest that the redesign utilizing a modified mass-customization framework achieved the intended purpose. Considering the different learning styles and orientations from the students who participated in this course, it is understandable that a distribution of assessments by the students would demonstrate a distribution across the scale utilized, yet the charts indicate that a shift in distribution to the higher end of the scale did occur. However, it appears that further refinement to the design structure may be necessary to further improve the student's interaction experience.

\section{Conclusions}

The results of the administered survey must be taken with caution. The sample size used for the pre- and post-design changes were small. Also, it should be noted that the students involved in this study were all adult graduate learnings. Further, $83 \%$ of the students surveyed for the pre-design change, and $52 \%$ of the students surveyed for the post-design change self-identified as being 'task-focused'. This suggests that these individuals were highly motivated, and this is in alignment with the work of Brocket (2016). Therefore, the suggested findings from this study may not be directly transferable to other post-secondary learning situations.

While improvement was noted for the eleven questions focusing on design structure and outcomes, the four questions that focused on the social relationship aspects of the design suggest that further modifications for the course design are appropriate. Therefore, further work should be undertaken to attempt to understand if their is a relation between learning styles and orientation, with the structure of the course.

An additional caution should be mentioned. The size of classes involved in this study were approximately 20 students with one class being only 13 students. At this modest size, it is relatively easy to keep track of individual students, their progress, and their needs. The students involved in this study were monitored utilizing a simple Excel spreadsheet. It is likely that this architecture for administrative purposes would scale reasonably well to a class of nearly 40 students. However, it is possible that this administrative function would be stressed if a class size exceeds 50 students.

Overall, only approximately $33 \%$ of the students chose to not follow the traditional path, although the final class involved in this study exceeded $50 \%$ for the self-selected path. It is not known if the difference in path selection is related to cohort 'personality', work and family responsibilities, or some other unknown factor. It is clear from student comments (noted earlier in this document) that life responsibilities had a significant impact on choice of paths. Further investigation should be undertaken to determine if modifications to the existing modified mass-customization design would impact student choice of learning path.

However, the preliminary results of this study suggest that a modified mass-customized course may be a concept worthy of further investigation. It is hoped that others improve on this idea.

\section{References}

Allitt, P. N. (2010). The art of teaching: Best practices from a master educator the teaching company. Chantilly, VA.

Antonancopoulou, E. (2006). The relationship between individual and organizational learning: New evidence from managerial learning practices. Management and Learning, 37(4), 455-273.

Antonancopoulous, E., \& Chiva, R. (2007). The social complexity of organizational learning. Management Learning, 38(3), $277-295$. 
Binsted, D. S. (1980). Design for learning in management training and development. Journal of European Industrial Training, 4(8), 1-32.

Brockbank, A., McGill, I., \& Beech, N. (2002). Reflective learning in practice. London: Gower

Brocket, R. G. (2016). Teaching adults: A practical guide for new teachers. San Francisco: Jossey-Bass.

Drummond, T. (2016). A brief summary of the best practices in college teaching. Available from North Seattle Community College: teaching.uncc.edu/learning-resources/books/best-practice//best-practices-summary [Accessed De-cember 10, 2016].

Elkhannoubi, H. B. (2016). User's behavior influence on cybersecurity strategy effectiveness. International Journal of Advanced Engineering Research and Science (IJAERS), 3(10): 188-196. Available at: http://dx.doi.org/10.22161/ijaers/3.10.30.

Hawk, T. F., \& Shah, A. J. (2007). Using learning style instruments to enhance student learning. Decision Sciences Journal of Innovative Education, 5(1), 1-19.

Honey, P., \& Mumford, A. (1992). Manual of learning styles (3rd ed.). London: Peter Honey.

Irfan, O. M. (2016). Effect of using 4mat method on academic achievement and attitudes toward engineering economy for undergraduate students. International Journal of Vocational and Technical Education, 8(1), 1-1 1.

Islam, A. N. (2013). Investigating e-learning system usage outcomes in the university context. Computers \& Education, 69, 387-399.

Kaufman, S. B., DeYoun, C. G., Gray, J. R., Jimenez, L., Brown, J., \& Mackintosh, N. (2010). Implicit learning as an ability. Cognition, $116(3), 321-340$

Kolb, D. A. (2014). Experiential learning: Experience as the source of learning and development. FT Press.

Kolbs, D. A., Rubin, I. M., \& McIntyre, J. M. (1984). Organizational psychology: An experiential approach. New York: Prentice Hall.

Macpherson, A., Jones, O., Zhang, M., \& Wilson, A. (2003). Reconceptualising learning spaces: Developing capabilities in a hi-tech small firm. Journal of Workplace Learning 15(6), 259-270.

Pashler, H., McDaniel, M., Rohrer, D., \& Bjork, R. (2008). Learning styles: Concepts and evidence. . Psychological Science in the Public Interest, 9(3), 105-119.

Pasupathi, M. (2012). How we learn the teaching company. Chantilly: VA.

Perry, J. K., Samuelson, L. K., Malloy, L. M., \& Schiffer, R. N. (2010). Learn locally, think globally: Exemplar variability sup-ports higher-order generalization and word learning. Psychological Science, 21(12), 1894-1902.

Rau, H. (2012). Student reflective practices. China-USA Business Review, 1 1(4), 564-580.

Raus, H. E. (2009). Online discussion and communities of practice. Business Education Innovation Journal, 1(2), 92-96.

Schaler, J. A. (2006). Howard gardner under fire: The rebel psychologist faces his critics. Peru, IL: Open Court Publishing.

Truong, H. M. (2015). Integrating learning styles and adaptive e-learning system: Current developments, problems and opportunities. Computers in Human Behavior, Available at: http://dx.doi.org/10.1016/j.chb.2015.02.014(55), $1185-1193$. 